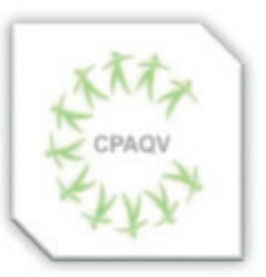

ISSN: $2178-7514$
ARTIGO DE REVISÃO

\section{MODELOS EXPERIMENTAIS EM ANIMAIS PARA PESQUISA NA ÁREA DE PERIODONTIA E IMPLANTODONTIA: REVISÃO DE LITERATURA}

\section{Experimental models in animals for research in the area of periodontics and implantodontics: literature review}

Talyssa Pequeno de Brito ${ }^{1}$; Flávia dos Santos Lima ${ }^{1}$; Caio Cavalcante da Rocha ${ }^{1}$

\begin{abstract}
RESUMO
Modelos animais são necessários para avaliar objetivamente a patogênese das doenças periodontais em seres humanos e suas várias modalidades de tratamento. Baseado nisso, foi realizada esta revisão de literatura tendo como foco suas indicações e contraindicações, benefícios para o paciente, bem como vantagens e desvantagens de cada modelo estudado. Para isso foi realizado um levantamento bibliográfico nas bases de dados Medline, Pubmed, Lilacs e Bireme, no período de 2006 até 2015, utilizando como palavras chave os termos: modelos experimentais, pesquisa cientifica; periodontia, implantodontia. $\mathrm{O}$ uso desses modelos vem sendo crucial para o desenvolvimento de novas técnicas e mudanças de paradigmas na pesquisa cientifica. Com base neste estudo, observou-se que modelos experimentais têm sido desenvolvidas de modo a reproduzir as principais doenças periodontais (gengivite, periodontite), sua patogênese e investigar novas técnicas cirúrgicas
\end{abstract}

Palavras-chave: modelos experimentais, pesquisa cientifica; periodontia; implantodontia

\begin{abstract}
Animal models are necessary to objectively evaluate the pathogenesis of periodontal diseases in humans and its various treatment modalities. Based on that, this literature review was performed focusing on its indications and contraindications, benefits for the patient as well as advantages and disadvantages of each model studied. Thus, we conducted a literature review in Medline, PubMed, Lilacs and Bireme databases, from 2006 to 2015 using as keywords the terms: experimental models, scientific research; periodontics, implantology. The use of these models has been crucial for the development of new techniques and changes of paradigms in scientific research. Based on this study, it was observed that experimental models have been developed in order to reproduce the main periodontal diseases (gingivitis, periodontitis), its pathogenesis and investigate new surgical techniques.
\end{abstract}

Keywords: experimental models, scientific research; periodontics, implantology 


\section{INTRODUÇÃO}

A experimentação animal se reveste de uma importância incalculável nas pesquisas científicas, contribuindo sobremaneira para o desenvolvimento da ciência e tecnologia. Sua vasta contribuição nos diferentes campos científicos vem promovendo ao longo dos anos a descoberta de medidas profiláticas e tratamentos de inúmeras enfermidades que acometem os seres vivos. Como exemplos de contribuições científicas advindas de estudos realizados em animais temse a descoberta da insulina, desenvolvimento de vacinas contra diversas doenças e a produção de soros. Os animais foram responsáveis por descobertas que permitiram o uso terapêutico de antibióticos e o tratamento de diversas doenças, evitando assim epidemias e epizootias, bem como o desenvolvimento de técnicas de transplantes de órgãos e a possibilidade do uso de fármacos anestésicos, antidepressivos, entre outros ${ }^{(1)}$

A ideia de utilização de animais em pesquisas surgiu, principalmente, por questões econômicas. Mesmo com o progresso de métodos alternativos nos últimos anos (estudos in vitro, culturas de células, etc.), os modelos animais ainda apresentam como principal vantagem $\mathrm{O}$ fornecimento de informações sobre o organismo como um todo, fato que não é conseguido com outros métodos ${ }^{(1)}$.

As doenças periodontais e a demanda por próteses fixas aumentam com o envelhecimento da população, o que indica claramente a crescente demanda no futuro de terapias inovadoras reconstrutivas. A destruição dos tecidos periodontais e peri-implantares ocorrem principalmente como consequência de uma reação inflamatória crônica que pode culminar na perda do dente ou do implante ${ }^{(2)}$.

Os modelos animais e culturas de células têm contribuído para novos conhecimentos em ciências biológicas, incluindo a periodontia e implantodontia. Embora células cultivadas possam ser usadas para estudar os processos fisiológicos que ocorrem durante a patogênese das doenças que acometem os tecidos de suporte, a resposta complexa do anfitrião responsável por esta doença não pode ser reproduzida in vitro. Entre o reino animal, roedores, coelhos, porcos, cães, e macacos têm sido utilizados para estudar a periodontite humana, cada um deles com vantagens e desvantagens ${ }^{(3)}$

\section{REVISÃO DE LITERATURA}

\section{HISTÓRICO}

A primeira manifestação social que tentou doutrinar as pesquisas que provocavam dor em animais vertebrados denominou-se Cruelty to Animals Act, redigida em Londres, em 1876, um ano após a anestesia geral ter sido introduzida como parte da atividade médica. Os idealizadores desse documento tiveram o objetivo de autorizar o Governo a licenciar cientistas, a regularizar os experimentos e a inspecionar as instituições de pesquisa ${ }^{(4)}$. 
Em 1959, Russell e Burch publicaram o livro The principles of humane experimental technique, no qual afirmaram que a boa pesquisa com animais deve respeitar três Rs: replacement, reduction e refinement. A substituição significava que, em vez de animais superiores, dever-se-iam utilizar formas de vida filogeneticamente mais primitivas ou experimentos simulados, com base em avanços tecnológicos. A redução sugeria que as pesquisas fossem realizadas com o menor número de animais e de procedimentos, que permitisse alcançar os objetivos do trabalho. O refinamento significava para esses autores a capacidade que os pesquisadores deveriam ter para improvisar métodos que reduzissem o sofrimento dos animais, oferecendo-lhes o maior conforto possível ${ }^{(4)}$.

Há cerca de cento e cinqüenta anos modelos de animais têm sido desenvolvidos para estudo das causas, mecanismos e terapêutica das doenças humanas. Habitualmente são referidos na literatura médica quatro tipos básicos de modelo: induzido, espontâneo, negativo e modelo órfão. Os dois primeiros são de longe os mais importantes. Como o nome subentende, modelos induzidos são situações nas quais a condição a ser investigada é induzida experimentalmente (5)

O avanço do conhecimento biológico requer muitas vezes o uso de animais vivos em perfeita qualidade e de uma larga variedade de espécies. Métodos alternativos devem ser utilizados sempre que apropriados. Adotando o Principio Internacional dos 3RS (refinement, reduction and replacement) estabelecido por Russel y Burch em 1959 e que pode assim ser resumido: 'Qualquer técnica que refine um método existente para diminuir a dor e o desconforto dos animais, que reduza seu número em um trabalho particular ou que substitua o uso de uma espécie animal por outra, de categoria inferior na escala zoológica, ou por métodos computadorizados ou "in vitro", deve ser considerado como método alternativo" ${ }^{(4)}$.

Dentro do contexto da pesquisa periodontal, modelos animais foram utilizados pela primeira vez para determinar a relação entre infecção e a resposta do hospedeiro, num esforço para compreender o processo da doença. Os dados foram obtidos em animais para definir a etiologia e patogênese da doença periodontal e perimplantar. ${ }^{(6)}$

\section{PAPEL DOS MODELOS}

\section{EXPERIMENTAIS}

As doenças periodontal e peri-implantar, são infecções complexas que resultam numa resposta inflamatória degradante do tecido.

Muitos sistemas in vitro fornecem fortes evidências para elucidar a resposta celular para bactérias e, consequentemente, definir as vias de sinalização que estão envolvidos nesta doença dinâmica. No entanto, é impossível explorar a complexa patogênese da periodontite ou da doença peri-implantar usando apenas métodos in vitro. ${ }^{(6)}$ 
São necessários sistemas para testar a segurança e eficácia dos dados adquiridos antes da transferência para seres humanos. Os testes em animais, são um pré-requisito para exposição clínica humana, é realizado numa gama de espécies, desde ratos de laboratório até animais maiores (tais como cães ou macacos). Em pesquisa odontológica, a espécie animal utilizada depende em grande parte da pergunta da pesquisa ou do modelo de doença ${ }^{(6)}$.

Os modelos animais têm contribuído para a geração de novos conhecimentos em ciências biológicas, incluindo a periodontia. A doença periodontal pode ocorrer naturalmente ou ser induzida experimentalmente em animais. Várias espécies têm sido utilizadas para estudar a patogênese da periodontite e avaliar modalidades terapêuticas contra a doença. Enquanto modelos animais mostraram uma grande quantidade de dados, é, por vezes, difícil de determinar se os resultados são aplicáveis aos seres humanos. Assim, um modelo simples e reproduzível que imite verdadeiramente a patogênese humana da doença periodontal ainda não foi descoberto. Este papel de modelos de animais induzidos experimentalmente é naturalmente utilizado para estudar diferentes aspectos das doenças periodontais. ${ }^{(3)}$

A fim de estudar a origem e a evolução da doença periodontal, o modelo animal deve ter características do processo da doença que são semelhantes aos encontrados em seres humanos. Estes estudos experimentais devem ter etiopatogenia e uso de índices semelhantes aos da prática clínica, como por exemplo, indice gengival, índice de cálculo, profundidade das bolsas subgengivais e perda de inserção dentária. Estes dados experimentais podem ser complementados com radiografias, ensaios de imunologia, determinação de tipo de bactérias e análise histológica ${ }^{(7)}$.

Entre esses modelos animais, o cão é um dos modelos comumente escolhido para o estudo periodontal por causa de sua elevada taxa de ocorrência de periodontite. No entanto, o periodonto natural de cães produz lesões periodontais inconsistentes com uma medida e localização de inflamação periodontal desigual. Portanto, um modelo experimental em periodontite tem sido proposto ${ }^{(8)}$.

A ocorrência de doenças periodontal aumenta com o envelhecimento e a etiopatogenia é semelhante a encontrada em seres humanos. Apesar de haver algumas diferenças na resposta inflamatória, bem como na população bacteriana, os cães são amplamente utilizados em pesquisas de gengivite e periodontite. O acúmulo de cálculo leva a gengivite ,mas contrário aos seres humanos, o tecido conjuntivo permanece quase normal em cães. A conversão da gengivite para periodontite não é um processo sistemático mas pode ser induzida experimentalmente quando ligaduras são fixadas ao redor dos dentes ${ }^{(7)}$. 


\section{TIPOS DE MODELOS}

No cão e no homem, a doença periodontal apresenta muitos aspectos semelhantes, como sua etiologia e fisiopatologia, os tecidos envolvidos, as características clínicas como a formação de bolsas periodontais a morfologia dos defeitos ocorridos naturalmente e as características de reparação e regeneração. Poucas características diferem, como, por exemplo, a ocorrência mais frequente de defeitos de furca classe III e o fato de a remodelação óssea ocorrer em velocidade aproximadamente um terço $(1 / 3)$ mais rápido em cães quando comparado com o ser humano ${ }^{(9)}$.

Os dentes permanentes dos cães consistem em 3 incisivos, 1 caninos, 4 prémolares e 3 molares na mandíbula e dois molares na maxila. Tendo em vista seu temperamento dócil e a susceptibilidade natural à doença periodontal, cães, particularmente, beagles são usados em pesquisa odontológica para o estudo da progressão da doença periodontal, regeneração guiada de tecidos, cicatrização de feridas e implantes dentários. Os fatores etiológicos da doença periodontal parecem ser idênticos em seres humanos e cães. Cães podem, por conseguinte, ser de valor como um modelo para gengivite experimental. $\mathrm{O}$ fato que é possível manter a saúde periodontal em locais onde a acumulação foi impedida confirma dados semelhantes em seres humanos ${ }^{(10)}$.

Em cães, a placa subgengival envolve predominantemente bactérias anaeróbicas gram negativas, cocos e bastonetes, P. gingivalis e F. nucleatum, semelhante às bactérias humanas. Suscetibilidade ou resistência à doença periodontal em diferentes raças é ditada principalmente por variações genéticas, em vez da dieta. Além disso, os cães são utilizados em manipulações cirurgicas, incluindo a cicatrização de feridas e regeneração de bolsas periodontais. Como limitação das doenças periodontais naturais, a extensão e localização das lesões periodontais não são sempre sincronizada em cães. Em cães, a largura completa da gengiva marginal também é afetada, em vez de apenas o tecido lateral para a parede da bolsa gengival. Além disso, cuidar regularmente, incluindo companhia diária, o exercício, espaço e manutenção, faz o uso de cães com menos desejável em estudos periodontais. ${ }^{(3)}$

$\mathrm{Na}$ concepção de qualquer estudo animal médico ou odontológico, é muitas vezes vantajoso selecionar um animal que é filogeneticamente semelhante aos seres humanos. A vasta gama de espécie de macacos permite adequada seleção para diferentes investigações. Cada espécie tem semelhanças exclusivas e dessemelhanças com os seres humanos. Os macacos têm estruturas bucais semelhantes com os seres humanos e têm a ocorrência natural de placa dental, cálculo e gengivite, mas pequeno aumento na profundidades de bolsas. A maioria têm dentição decídua e permanente semelhante com a do ser humano, embora o tamanho dos dentes são dramaticamente menor. A organização do colágeno, da fibra gengival e periodontal no tecido conjuntivo, também são semelhantes as dos seres 
humanos. Clinicamente e histologicamente a gengiva saudável do macaco é indistinguíveis da gengiva humana. A mudança na composição da flora bacteriana de uma gengivite do início a uma fase posterior é também comparável para seres humanos. ${ }^{(10)}$

Estudos experimentais realizados em macacos são altamente relevantes para a prática clínica humana como eles apresentam anatomia parecida desenvolvem doenças periodontais com sintomas clínicos semelhantes. No entanto, a investigação experimental em macacos requer uma justificativa ética forte para o cuidado e uso levando em consideração a compra, despesas de transporte e de habitação destes animais por longos períodos. ${ }^{(7)}$

Nos primeiros estudos experimentais, os critérios de seleção de animais não eram bem definidos. A seletividade foi decorrente do número de trabalhos realizados e da identificação dos animais com os temas estudados. Animais de várias espécies têm sido utilizados ao longo desses últimos dois séculos de desenvolvimento científico, mas dentre todos eles o camundongo é, inquestionavelmente, o mais intensamente utilizado e o mais profundamente conhecido cientificamente. ${ }^{(1)}$

Os ratos não são susceptíveis ao desenvolvimento de periodontite natural. A inflamação crônica leva à destruição periodontal que pode ser induzida através da colocação de algodão ou ligaduras de seda nos sulcos ao redor dos molares. A inflamação crônica também pode ser conseguida por injeção intragengival de bactérias e lipopolissacarídeo, provocando a liberação de citocinas pró inflamatórias derivados do hospedeiro. Ambos os modelos são adequados para avaliar a patogênese da periodontite e estudar estratégias terapêuticas para modular a progressão da doença (2)

Camundongos, ratos e hamsters proporcionam várias vantagens para avaliação da microbiota e de resposta de acolhimento. Roedores têm apenas um incisivo e três molares em cada quadrante. Estudos usando roedores mostraram facilidade no desenvolvimento, após a colocação de ligaduras no sulco gengival em torno dos dentes molares, por meio de um aumento da acumulação de biofilme. Este modelo não pode reproduzir todos os aspectos da periodontite humana iniciação e progressão; no entanto, os ratinhos são modelos animais uteis para entender as interações hospedeiro-parasita. ${ }^{(6)}$

Os ratos são modelos relevante para a investigação periodontal experimental. A estrutura da área gengival dental é muito semelhante ao observado em seres humanos. No entanto, a ocorrência de doenças periodontais em ratos é menos freqüente do que em humanos, embora a patologia possa ser induzida por inoculação de bactérias, inserção de dieta rica em carboidratos e fixação de ligaduras ao redor dos dentes. Este modelo experimental não é ideal para o estudo da evolução da doença ao longo de grandes períodos de utilização por causa da histologia, do crescimento contínuo e migração 
dos dentes. Este modelo é amplamente usado para microbiológica e estudos imunológicos ${ }^{(7)}$

Além disso, a utilização de animais gnobioticos ou livres de germes parece ser muito interessante para as oportunidades que dão para a realização de monoinfecções por bácterias periodontopatógenos de origem humana. A etiopatogenia das doenças periodontais em hamsters é semelhante à dos ratos. ${ }^{(7)}$

A maior parte da pesquisa na área básica é empreendida nos animais de pequeno porte (camundongo, rato, hamster, cobaio, ou o gerbil) e compreendem quase $90 \%$ do total das espécies utilizadas nos laboratórios. Definir o modelo ideal não é tarefa fácil. Quanto mais se aproxima, em suas características fisiológicas, anatômicas e orgânicas ao ser humano, maior a aplicabilidade das conclusões obtidas. Preliminarmente o pesquisador deve delinear seus objetivos. O estudo da anatomia comparada dos animais vertebrados, fundamentado na escala filogenética é etapa fundamental para a concepção de um modelo adequado e generalizável ${ }^{(11)}$

O modelo periodontal do rato tem sido frequentemente utilizado para estudos de regeneração óssea. É um valioso modelo de rastreio para avaliação da moléculas regenerativas por causa da relação custo-eficácia, a facilidade de manuseio, etc. No entanto, o tamanho do defeito típico é relativamente pequeno, tornando a visualização um trabalho desafiador exigindo o uso de microscópios para a criação de defeitos cirúrgicos. Modelos animais grandes, tais como o cão ou macacos, são o próximo passo lógico. O cinética de cicatrização de feridas dos cães e anatomia dos dentes têm muitas semelhanças com a situação humana. Os macacos são altamente desejáveis para avaliar a segurança e eficácia de novas moléculas porque suas características anatômicas e biológicas são muito semelhantes as dos seres humanos. No entanto, o seu elevado custo e as dificuldades de manuseio de impedir que sejam amplamente utilizados. ${ }^{(12)}$

\section{CONCLUSÃO}

Modelos experimentais na área da periodontia e implantodontia são essenciais para a compreensão da origem e evolução da patologia em seres humanos. A utilização de modelos animais em pesquisa periodontal é um passo necessário antes de experimentações clínica com novos biomateriais e tratamentos $\mathrm{A}$ anatomia, fisiologia e patogenicidade de modelos experimentais devem ser semelhante a de seres humanos, a fim de demonstrar a segurança e eficácia de novos biomateriais, implantes ou tratamentos em regeneração periodontal. 


\section{REFERÊNCIAS}

1. Chorilli M, Michelin DC, Salgado HRN. Animais de laboratório: O camundongo. Rev Ciencias Farm Basica e Apl. 2007;28(1):11-23.

2. Pellegrini G, Seol YJ, Gruber R, Giannobile W V. Pre-clinical models for oral and periodontal reconstructive therapies. J Dent Res. 2009;88(12):106576.

3. Oz HS, Puleo D a. Animal models for periodontal disease. J Biomed Biotechnol. 2011;2011.

4. Princípios Internacionais para a Pesquisa Biomédica Envolvendo Animais. 1987; (January).

5. Fagundes DJ, Taha MO. Modelo animal de doença: critérios de escolha e espécies de animais de uso corrente. Acta Cir Bras. 2004;19(1):59-65.

6. Animal models for periodontal regeneration and peri-implant responses. 2015;68(92):66-82.

7. Struillou X, Boutigny H, Soueidan A, Layrolle P. Experimental animal models in periodontology: a review. Open Dent J. 2010;4:37-47.

8. Do MJ, Kim K, Lee H, Cha S, Seo T, Park HJ, et al. Development of animal experimental periodontitis models. J Periodontal Implant Sci. 2013;43(4):147-52.

9. Correna E, Reis C, Junqueira R, Carlo D. Regeneração periodontal em cães Periodontal regeneration in dogs. 2011;2128-36.

10. Weinberg $\mathrm{M}$ a, Bral M. Laboratory animal models in periodontology. J Clin Periodontol. 1999;26(6):335-40.

11. Karapolat $\mathrm{S}$. The use of animals in experimental studies. J Bras Pneumol. 2008;34(11):989; author reply 990.

12. Wound models for periodontal and bone regeneration : the role of biologic research. 2015;68:720 .

OBSERVAÇÃO: Os autores declaram não existir conflitos de interesse de qualquer natureza. 